\title{
Effect of long term dietary supplementation with plant extract on meat quality in heavy pigs
}

\author{
C. Corino ${ }^{1}$, G. Pastorelli ${ }^{1}$, R. Rossi ${ }^{1}$, S. Ratti ${ }^{1}$ and G. Maiorano ${ }^{2}$ \\ ${ }^{1}$ University of Milan, Department of Health, Animal Science and Food Safety, Milan Italy and ${ }^{2}$ University of Molise, \\ Department of Agricultural, Environmental and Food Sciences, Via De Sanctis snc, 86100 Campobasso, Italy
}

In the recent years, considerable attention has been focused to the improvement of meat quality parameters. Some plant extracts contain phenylpropanoid glycosides have many biological activities such as anti-inflammatory, antimicrobic and antioxidant. Verbascoside, are the most abundant compounds in Verbenaceae extracts ${ }^{(1)}$. The objective of the present study was to assess the efficacy of long term supplementation of porcine diets with natural extract contained verbascoside on meat quality parameters of Longissimus dorsi (LD) muscle in heavy pigs. The trial was performed in Italy where to obtain high quality cured products pig were slaughter at 9 months of age and $160-170 \mathrm{~kg}$ live weight to provide heavy cuts with excellent meat quality. Twenty Dalland female pigs fed a control diet (C) or a diet supplemented with plant extract (PE) (5 mg verbascoside/kg feed) from weaning to slaughter $(169.8 \mathrm{~kg})$. The animals fed a corn-based diet, containing the same amount of vitamin E. At slaughter, the left LD muscles were sampled. The $\mathrm{pH}$ at $24 \mathrm{~h}$, colour indices, shear force, total losses ${ }^{(2)}$ and chemical ${ }^{(3)}$ parameters were investigated. Cholesterol was extracted using the method of Maraschiello et al. ${ }^{(4)}$. Data were analyzed by one way ANOVA with dietary treatment as the main effect. The $\mathrm{pH}$ and colour indices are in line with those reported in literature for heavy pigs ${ }^{(5,6)}$. Total losses (drip and cooking loss) resulted lower in LD muscle of PE group than control. This data are in agreement with Kołodziej-Skalska et al. ${ }^{(7)}$ that reported a lower drip and cooking losses values in LD muscle of pig fed plant extract compared with the control group. Cholesterol content was affected by dietary treatment, resulting lower in LD muscle from PE group than control. No other chemical parameters was affected.

\begin{tabular}{lcccl}
\hline & Control & PE & SEM & $P$ \\
\hline $\mathrm{pH}$, 24h & 5.56 & 5.55 & 0.02 & 0.834 \\
Drip Loss, \% & 3.42 & 2.93 & 0.13 & 0.068 \\
Cooking Loss, \% & 16.15 & 15.34 & 0.27 & 0.146 \\
Total Losses, \% & 19.02 & 17.82 & 0.29 & 0.038 \\
Shear Force, $\mathrm{kg} / \mathrm{cm}^{2}$ & 2.54 & 2.30 & 0.07 & 0.130 \\
Cholesterol, $\mathrm{mg} / 100 \mathrm{~g}$ & 57.8 & 51.0 & 1.78 & 0.047 \\
\hline
\end{tabular}

Long term dietary supplementation with PE containing verbascoside positively affect LD meat quality parameters. The data on total losses result interesting from a technological point of view. The reduction of cholesterol content improve the nutritional quality of meat for fresh consumption. Further studies are needed to clarify the optimal length of PE dietary supplementation and to investigate its effect on sensory parameters.

1. Pereira DM, Valentao P, Pereira JA et al. (2009) Molecules 14, 2202-2211.

2. Honikel KO (1998) Meat Sci 49, 447-457.

3. AOAC (2000) Official Methods of Analysis (17th ed.), Gaithersburg, MD, USA.

4. Maraschiello C, Diaz I, Garcia Regueiro JA (1996) J High Resol Chromatogr 19, 165-168.

5. Corino C, Magni S, Pagliarini E et al. (2002) Meat Sci 60, 1-8.

6. Corino C, Rossi R, Musella M et al. (2009) J Sci Food Agric 89, 463-469.

7. Kołodziej-Skalska A, Rybarczyk A, Matysiak B et al. (2011) Acta Agricult Scand 6, 80-85. 